\title{
Neck-specific exercise program
}

Description of neck specific exercise program as used by Maria Landén Ludvigsson, Anneli Peolsson, Gunnel Peterson in a randomized study comparing exercise approaches in chronic whiplash "Effects of neck-specific exercise with or without a behavioural approach in addition to prescribed physical activity for individuals with chronic whiplash-associated disorders: a prospective randomised study"

Peolsson A, Landen Ludvigsson M, Overmeer T, Dedering A, Bernfort L, Johansson G, Kammerlind AS, Peterson G. Effects of neck-specific exercise with or without a behavioural approach in addition to prescribed physical activity for individuals with chronic whiplash-associated disorders: a prospective randomised study. BMC Musculoskelet Disord 2013;14:311. http://dx.doi.org/ 10.1186/1471-2474-14-311

Further papers by copyright holders may reference to this program.

DOI link to this program: http://dx.doi.org/10.3384/report.diva-113865

Copyright: Gunnel Peterson/ Maria Landén Ludvigsson/Anneli Peolsson. This document is intended for physiotherapists only and may be copied and used by physiotherapists in their professional clinical conduct, with due credit given to the authors. The exercises shall be reassessed by trained professionals and may need adjustments in each specific case. Furthermore, the results presented in this document are the result of university research and shall not be seen as a commercial product. The authors shall have no liability whatsoever for any use. All responsibility for the congruity and use of the contents herein rests entirely with the therapist using it. No alterations to this document, or further distribution in any form without explicit permission from copyright holders, is allowed, except with regards to the rights previously mentioned. 


\section{$\underline{\text { Neck specific exercise part } 1}$}

Make sure the patient is lying in supine in a neutral position without protraction or retraction of the head. The jaw should be relaxed, keeping the lips together but teeth apart and tongue relaxed. The aim is to facilitate deep neck muscle activity, without superficial muscle activity. The therapist palpates at the chosen cervical level to guide the patient and make sure superficial activity is minimal while deeper activation is felt in extension/rotation. (In flexion only superficial palpation is possible). Hold each position for about 5 seconds. Increase repetitions step-by-step and modify duration and repetitions to accommodate the needs and tolerance of each individual patient. A common level to start with is 5 repetitions 3 times a day. The exercises should not provoke the patient's neck pain.

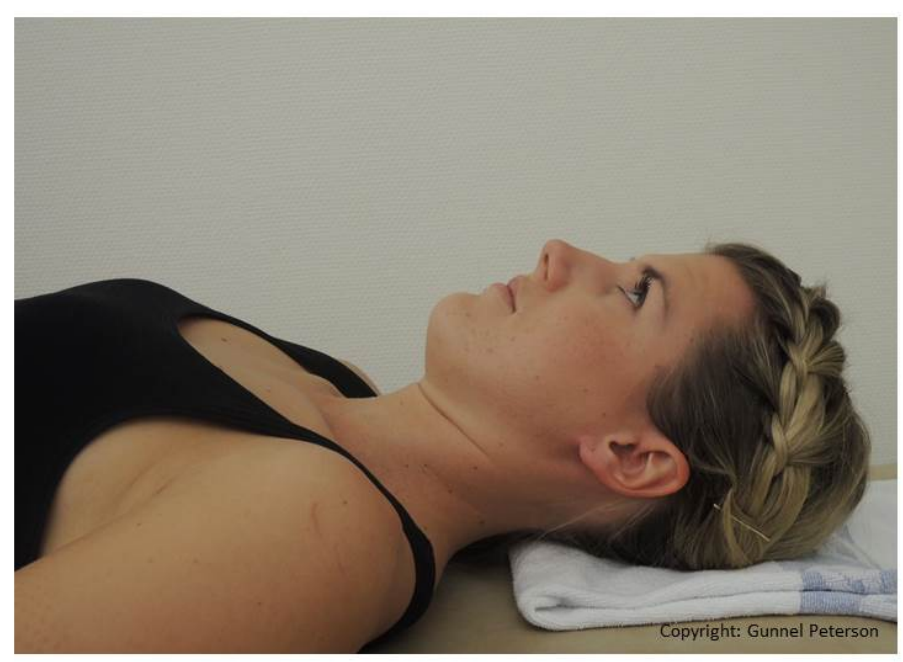

Ask the patient to visualize extending the head, but without performing any neck movement. Ask the patient to follow the imaginary extension with their eyes, looking up/back. The patient should hold this position for about 5 seconds to start with. Increase repetitions step by step and modify duration and repetitions to accommodate the needs of each patient.

Copyright: Gunnel Peterson/ Maria Landén Ludvigsson/Anneli Peolsson. This document is intended for physiotherapists only and may be copied and used by physiotherapists in their professional clinical conduct, with due credit given to the authors. The exercises shall be reassessed by trained professionals and may need adjustments in each specific case. Furthermore, the results presented in this document are the result of university research and shall not be seen as a commercial product. The authors shall have no liability whatsoever for any use. All responsibility for the congruity and use of the contents herein rests entirely with the therapist using it. No alterations to this document, or further distribution in any form without explicit permission from copyright holders, is allowed, except with regards to the rights previously mentioned. 


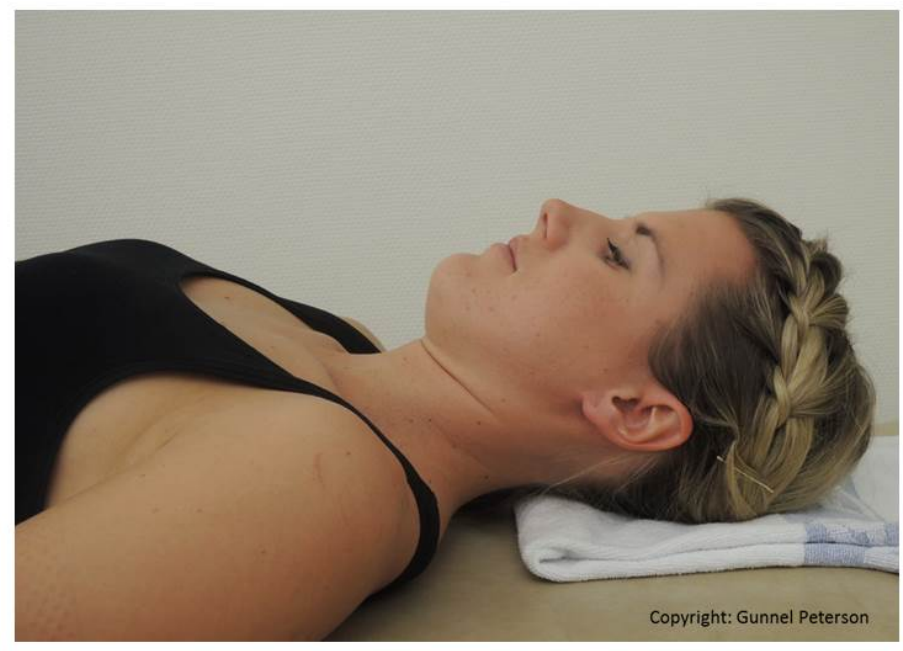

\begin{tabular}{|l|}
\hline Ask the patient to visualize \\
flexing (nodding) the head, but \\
without performing any neck \\
movement. Ask the patient to \\
follow the imaginary flexion \\
with their eyes, looking down \\
towards their chest. \\
\hline
\end{tabular}

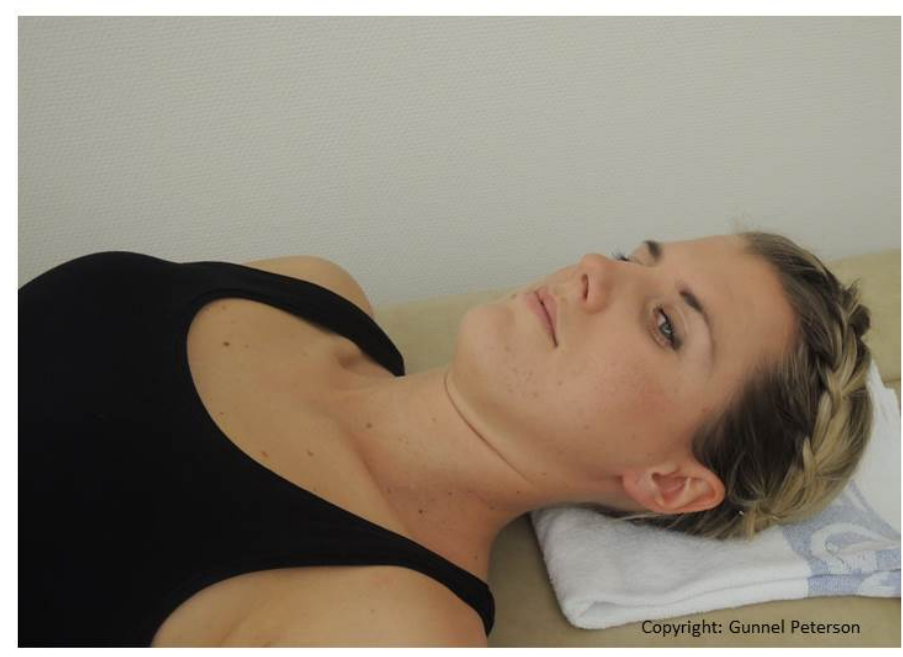

Ask the patient to visualize
rotating the head, but without
performing any neck movement.
Ask the patient to follow the
imaginary rotation with their eyes
to the same side. Switch to the
other side.

When patients master this activation move on to the next program (Neck specific exercise 2)

Copyright: Gunnel Peterson/ Maria Landén Ludvigsson/Anneli Peolsson. This document is intended for physiotherapists only and may be copied and used by physiotherapists in their professional clinical conduct, with due credit given to the authors. The exercises shall be reassessed by trained professionals and may need adjustments in each specific case. Furthermore, the results presented in this document are the result of university research and shall not be seen as a commercial product. The authors shall have no liability whatsoever for any use. All responsibility for the congruity and use of the contents herein rests entirely with the therapist using it. No alterations to this document, or further distribution in any form without explicit permission from copyright holders, is allowed, except with regards to the rights previously mentioned. 


\section{Neck specific exercise part 2}

Make sure the patient is lying in supine in a neutral position without protraction or retraction of the head, and that the jaw is relaxed, keeping the lips together but teeth apart and tongue relaxed. The aim is to facilitate deep neck muscle activity, without superficial muscle activity. The therapist palpates at the chosen cervical level to guide the patient in force and performance, thus minimizing superficial activity while deeper activation is felt in extension/rotation. (In flexion only superficial palpation is possible). Use the hand of the patient (or therapist) as resistance to the isometric contraction. Keep the positions for about 5 seconds. Increase repetitions step by step and modify duration and repetitions to accommodate the needs and tolerance of each patient. A common level to start with is 5 repetitions 3 times a day. The exercises should not provoke the patient's neck pain. When patients master these exercises in supine, progress to an upright sitting position with initial postural correction if needed.

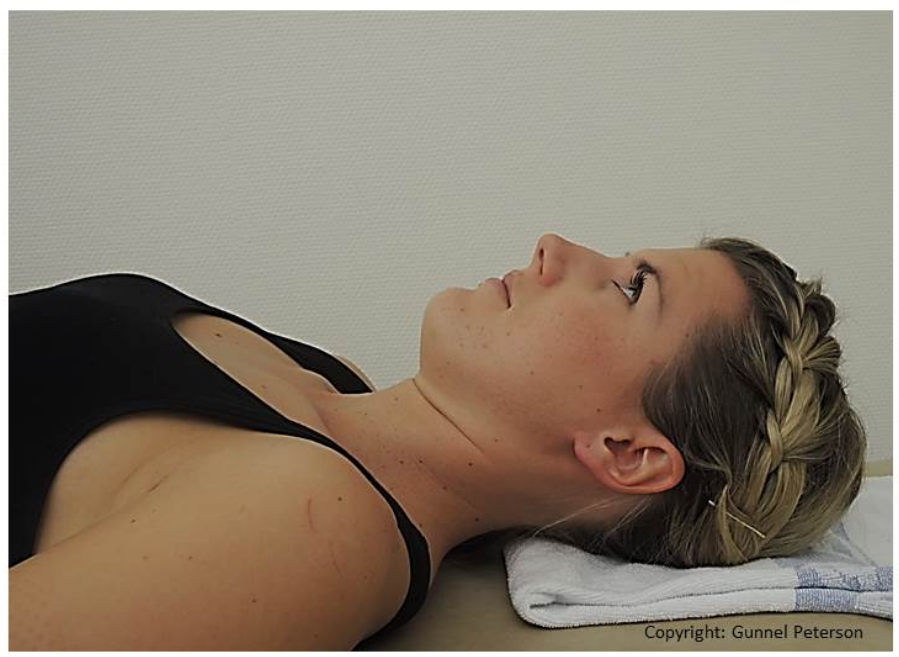

Ask the patient to gently push the back of the head against the plinth, performing an isometric extension (NOT retraction). Ask the patient to follow the imaginary extension with their eyes, looking up/back. The patient should hold this position for about 5 seconds to start with. Increase repetitions step by step and modify duration and repetitions to accommodate the needs of each patient.

Copyright: Gunnel Peterson/ Maria Landén Ludvigsson/Anneli Peolsson. This document is intended for physiotherapists only and may be copied and used by physiotherapists in their professional clinical conduct, with due credit given to the authors. The exercises shall be reassessed by trained professionals and may need adjustments in each specific case. Furthermore, the results presented in this document are the result of university research and shall not be seen as a commercial product. The authors shall have no liability whatsoever for any use. All responsibility for the congruity and use of the contents herein rests entirely with the therapist using it. No alterations to this document, or further distribution in any form without explicit permission from copyright holders, is allowed, except with regards to the rights previously mentioned. 


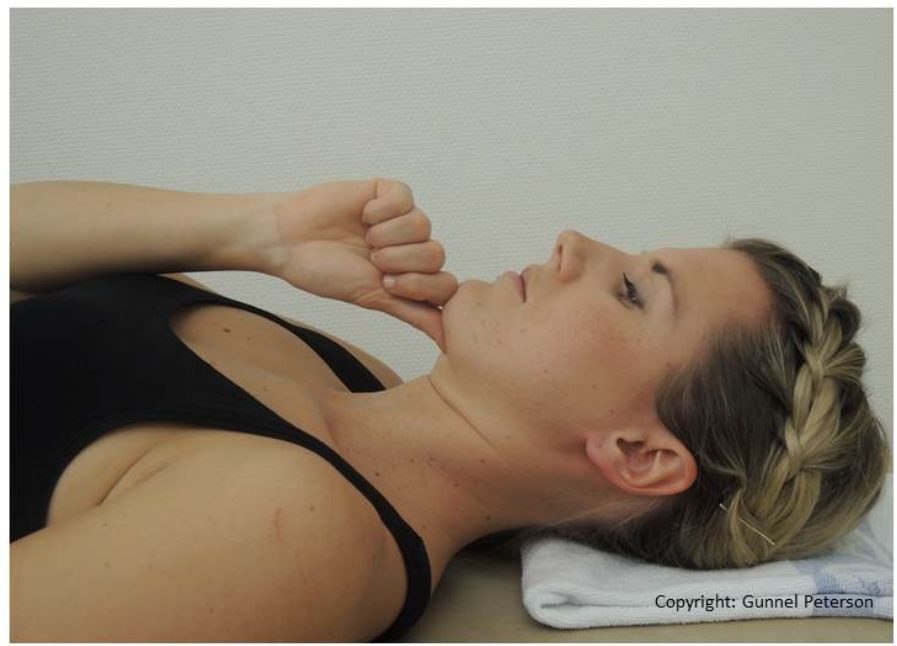

Put a hand as resistance against the chin. Ask the patient to gently perform an isometric nod. Ask the patient to follow the imaginary flexion with their eyes, looking down towards the chest. The patient should hold this position for about 5 seconds to start with. Increase repetitions step by step and modify duration and repetitions to accommodate the need of each patient.

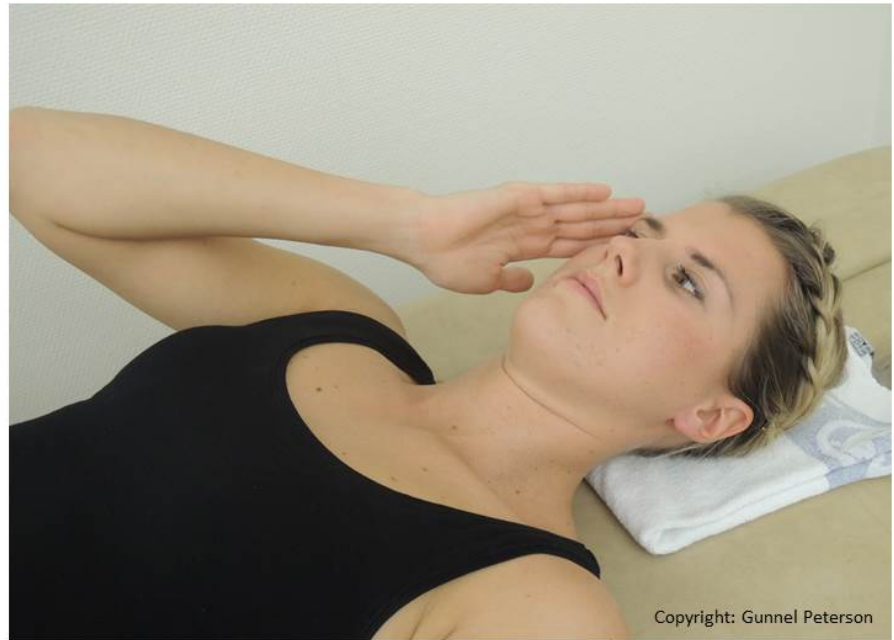

Put a hand as resistance against the temple. Ask the patient to gently perform an isometric rotation. Ask the patient to follow the imaginary rotation with their eyes, looking to the same side. The patient should hold this position for about 5 seconds to start with. Increase repetitions step by step and modify duration and repetitions to accommodate the need of each patient. Switch to the other side.

When patients master this activation move on to the next program (Neck specific exercise 3 )

Copyright: Gunnel Peterson/ Maria Landén Ludvigsson/Anneli Peolsson. This document is intended for physiotherapists only and may be copied and used by physiotherapists in their professional clinical conduct, with due credit given to the authors. The exercises shall be reassessed by trained professionals and may need adjustments in each specific case. Furthermore, the results presented in this document are the result of university research and shall not be seen as a commercial product. The authors shall have no liability whatsoever for any use. All responsibility for the congruity and use of the contents herein rests entirely with the therapist using it. No alterations to this document, or further distribution in any form without explicit permission from copyright holders, is allowed, except with regards to the rights previously mentioned. 


\section{Neck specific exercise, part 3 GYM}

Choose one or two exercises in each direction. A common level to start with is $5-10$ repetitions. Increase repetitions step-by-step and modify to accommodate the needs and tolerance of each patient individually. The aim is to enhance endurance with a high number of repetitions (up to $3 \times 20-30$ if tolerated). The exercises should not provoke the patient's neck pain or other unwanted symptoms like radiating sensations, paresthesia, nausea etc.

Pulley exercises

Exercises using the pulley are preferred because they can be more easily progressed in a controlled manner, and are similar to the home exercises, preparing patients to be able to exercise by themselves in a well-functioning way. The patient sits in an upright position with sling around the head, and the band attached at the pulley at the height of the forehead/eyes. Women generally need lower load than men (benchmark, women $0.5 \mathrm{~kg}(1.1 \mathrm{lb})$, men $1 \mathrm{~kg}$ $(2.2 \mathrm{lbs})$ to start with). Adjust posture if needed (neutral or a slight retraction). Ask the patient to keep the head straight in line with the torso throughout the movement. The first 3 pulley exercises are isometric. Correct the posture continuously if necessary. A common reason for pain provocation is failure to maintain a correct posture.

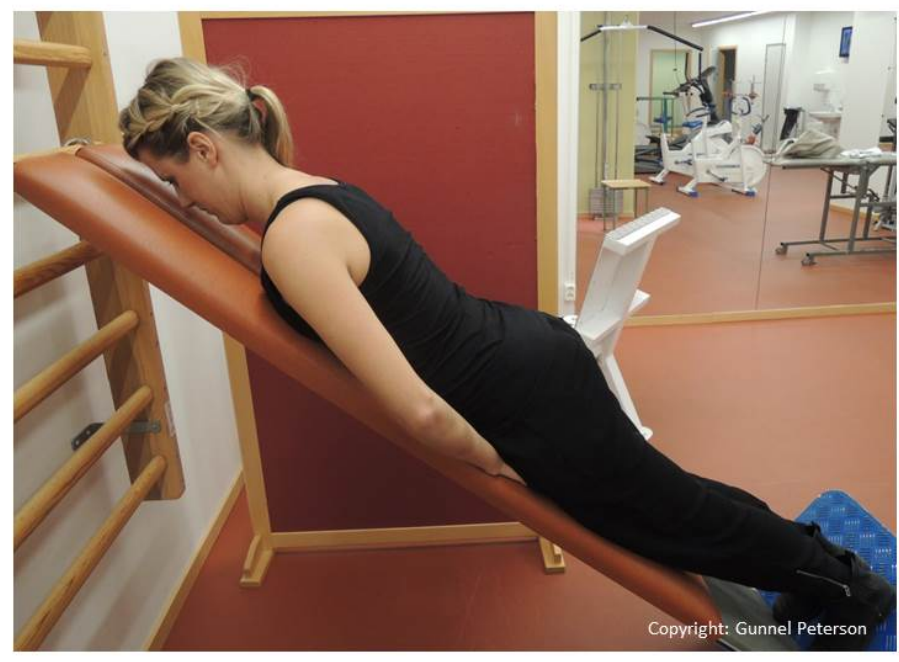

Place the guild board at the appropriate height (higher attachment is less strenuous than- a lower attachment). Ask the patient to keep the chin retracted. Extend neck and torso with the whole torso/neck/head in a straight line.

Copyright: Gunnel Peterson/ Maria Landén Ludvigsson/Anneli Peolsson. This document is intended for physiotherapists only and may be copied and used by physiotherapists in their professional clinical conduct, with due credit given to the authors. The exercises shall be reassessed by trained professionals and may need adjustments in each specific case. Furthermore, the results presented in this document are the result of university research and shall not be seen as a commercial product. The authors shall have no liability whatsoever for any use. All responsibility for the congruity and use of the contents herein rests entirely with the therapist using it. No alterations to this document, or further distribution in any form without explicit permission from copyright holders, is allowed, except with regards to the rights previously mentioned. 


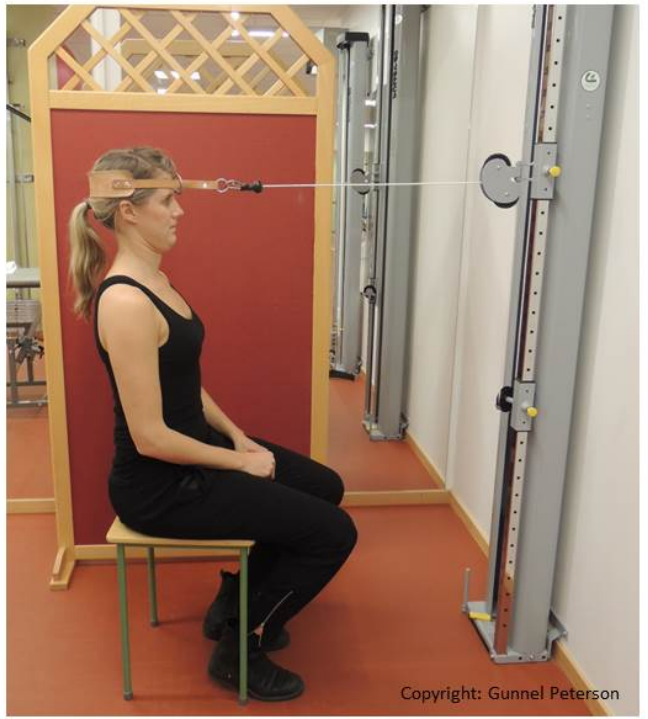

Without extending or flexing the head, ask the patient to lean the whole torso/neck/head in a straight line backwards about 10-20 centimeters (4-8 inches).

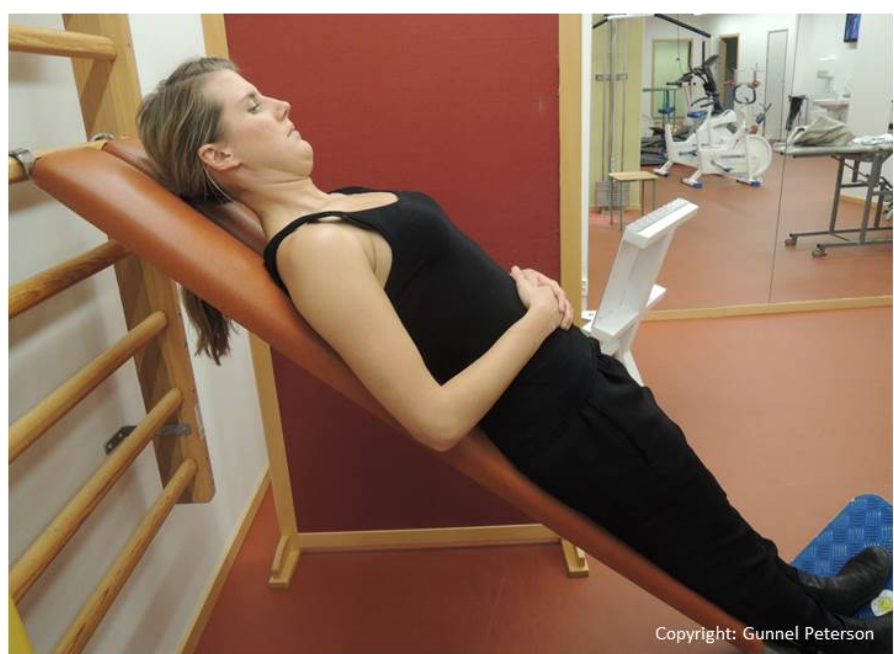

Place the guild board at the appropriate height (higher attachment is less strenuous than a lower attachment). Ask the patient to keep the chin retracted, and lift the head slightly from the guild board.

Copyright: Gunnel Peterson/ Maria Landén Ludvigsson/Anneli Peolsson. This document is intended for physiotherapists only and may be copied and used by physiotherapists in their professional clinical conduct, with due credit given to the authors. The exercises shall be reassessed by trained professionals and may need adjustments in each specific case. Furthermore, the results presented in this document are the result of university research and shall not be seen as a commercial product. The authors shall have no liability whatsoever for any use. All responsibility for the congruity and use of the contents herein rests entirely with the therapist using it. No alterations to this document, or further distribution in any form without explicit permission from copyright holders, is allowed, except with regards to the rights previously mentioned. 


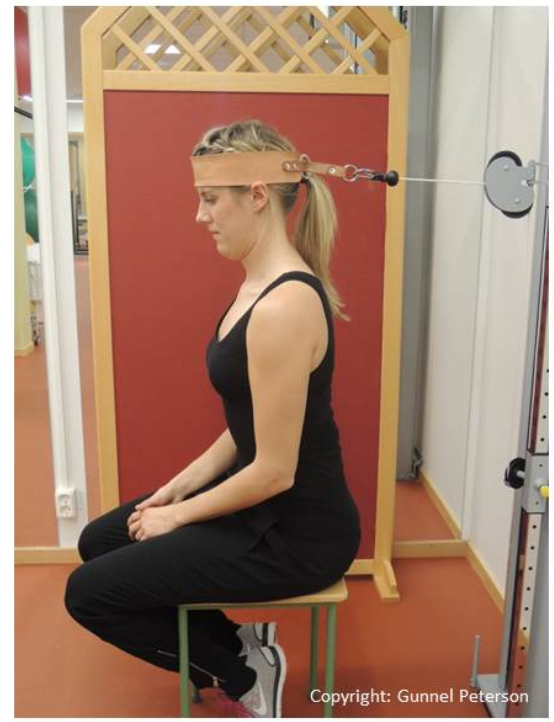

Without extending or flexing the neck, ask the patient to lean the whole torso/neck/head in a straight line forwards about 10-20 centimeters (4-8 inches). Make sure there is no protraction.

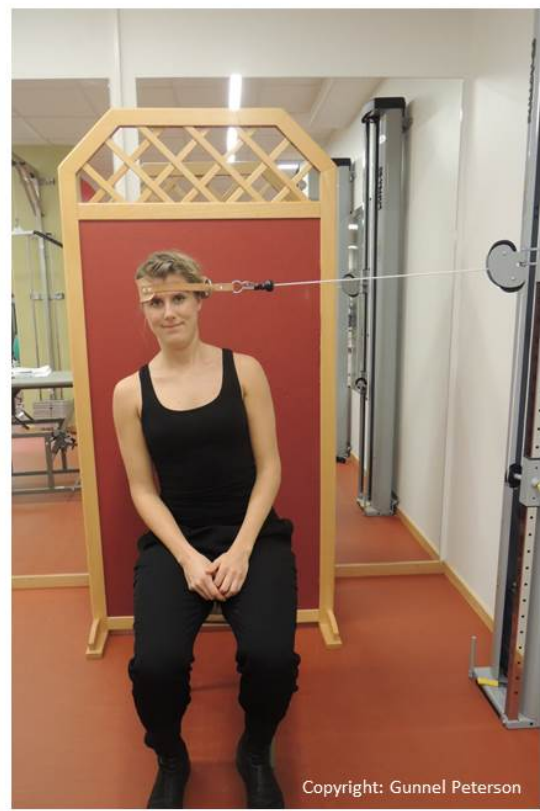

Without any movement of the neck, ask the patient to lean the whole torso/neck/head in a straight line to one side about 10 centimeters (4 inches).

Switch to the other side.

Copyright: Gunnel Peterson/ Maria Landén Ludvigsson/Anneli Peolsson. This document is intended for physiotherapists only and may be copied and used by physiotherapists in their professional clinical conduct, with due credit given to the authors. The exercises shall be reassessed by trained professionals and may need adjustments in each specific case. Furthermore, the results presented in this document are the result of university research and shall not be seen as a commercial product. The authors shall have no liability whatsoever for any use. All responsibility for the congruity and use of the contents herein rests entirely with the therapist using it. No alterations to this document, or further distribution in any form without explicit permission from copyright holders, is allowed, except with regards to the rights previously mentioned. 


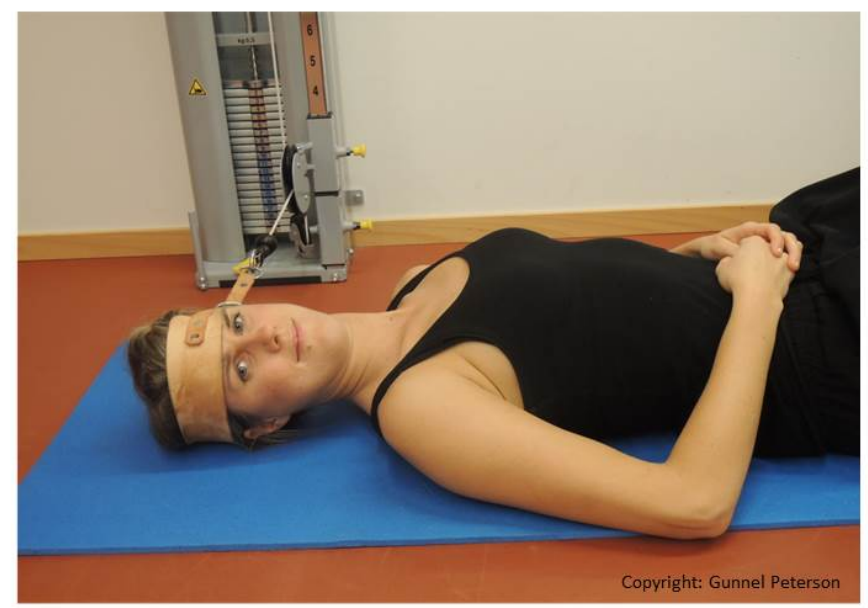

Lower the pulley. Lying in supine on a mat with the chin tucked-in, ask the patient to rotate to the opposite side of the pulley. If even the lowest weight $(0.5 \mathrm{kilo} / 1.1 \mathrm{lb})$ is too heavy, the patient can assist the movement by simultaneously pulling gently in the same direction with the hand on the side of the pulley.

Switch sides.

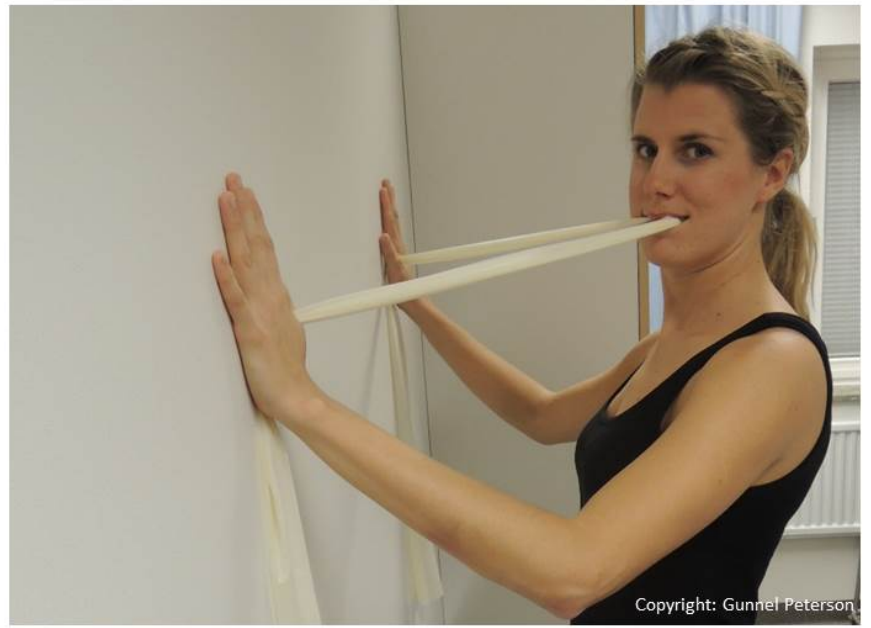

In a standing position, hold the ends of the rubber band against a wall, with the patient's hands well apart (do not lean against the wall). Keeping the middle of the rubber band gently between the teeth, slowly turn the head from side-to-side.

Copyright: Gunnel Peterson/ Maria Landén Ludvigsson/Anneli Peolsson. This document is intended for physiotherapists only and may be copied and used by physiotherapists in their professional clinical conduct, with due credit given to the authors. The exercises shall be reassessed by trained professionals and may need adjustments in each specific case. Furthermore, the results presented in this document are the result of university research and shall not be seen as a commercial product. The authors shall have no liability whatsoever for any use. All responsibility for the congruity and use of the contents herein rests entirely with the therapist using it. No alterations to this document, or further distribution in any form without explicit permission from copyright holders, is allowed, except with regards to the rights previously mentioned. 


\section{Home exercise (complementary to resistive exercise in gym), part 4}

The patient sits in an upright position with a low-load rubber band attached at the height of the forehead/eyes. Women generally need lower load than men. Adjust posture if needed (neutral or a slight retraction). Ask the patient to keep the head straight in line with the torso throughout the movement. The first 3 exercises are isometric. Increase repetitions step by step and modify to accommodate the needs and tolerance of each patient. The aim is to enhance endurance with a high number of repetitions. Correct the posture continuously if necessary. The exercises should not provoke the patient's neck pain or other unwanted symptoms like radiating sensations, paresthesia etc. A common reason for pain provocation is protracted posture.

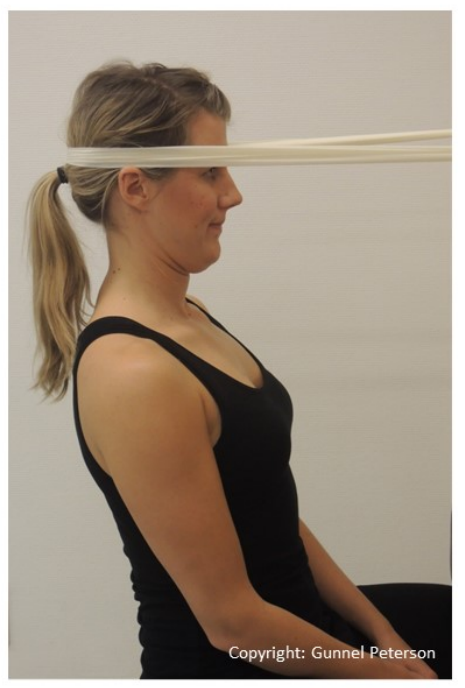

Without extending or flexing the head, ask the patient to lean the whole torso/neck/head in a straight line backwards about 10-20 centimeters (4-8 inches).

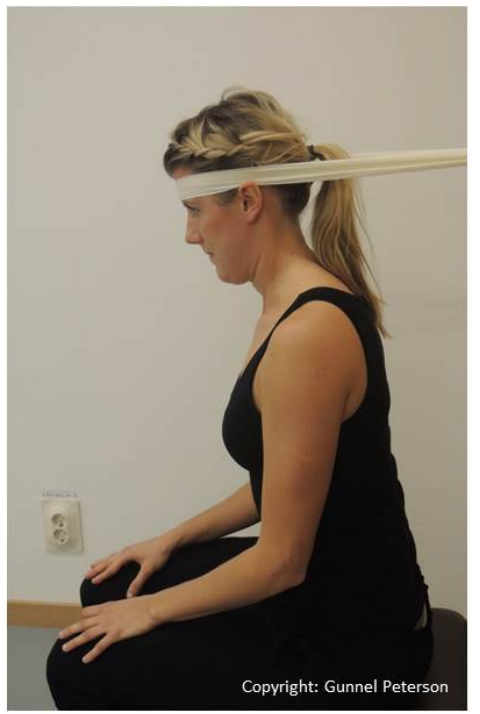

Without extending or flexing the neck, lean the whole torso/neck/head in a straight line forwards about 10-20 centimeters (4-8 inches). Make sure there is no protraction.

Copyright: Gunnel Peterson/ Maria Landén Ludvigsson/Anneli Peolsson. This document is intended for physiotherapists only and may be copied and used by physiotherapists in their professional clinical conduct, with due credit given to the authors. The exercises shall be reassessed by trained professionals and may need adjustments in each specific case. Furthermore, the results presented in this document are the result of university research and shall not be seen as a commercial product. The authors shall have no liability whatsoever for any use. All responsibility for the congruity and use of the contents herein rests entirely with the therapist using it. No alterations to this document, or further distribution in any form without explicit permission from copyright holders, is allowed, except with regards to the rights previously mentioned. 


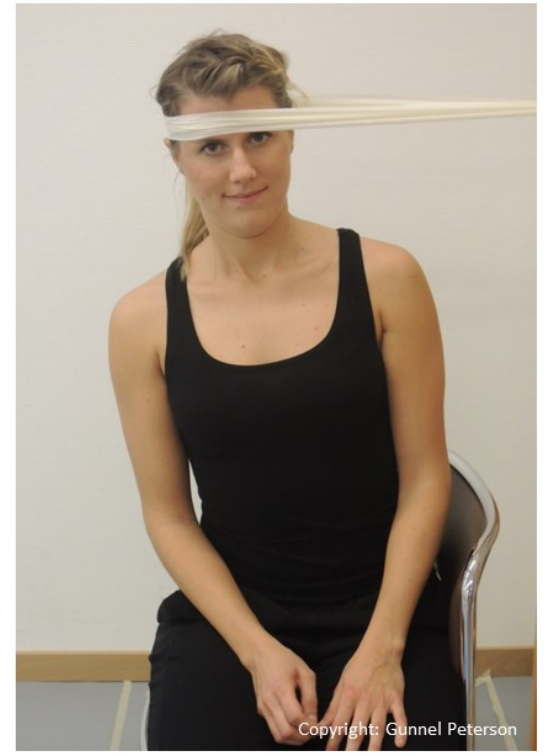

Without any movement of the neck, lean the whole torso/neck/head in a straight line to one side about 10 centimeters (4 inches).

If needed bilaterally, switch to the other side.

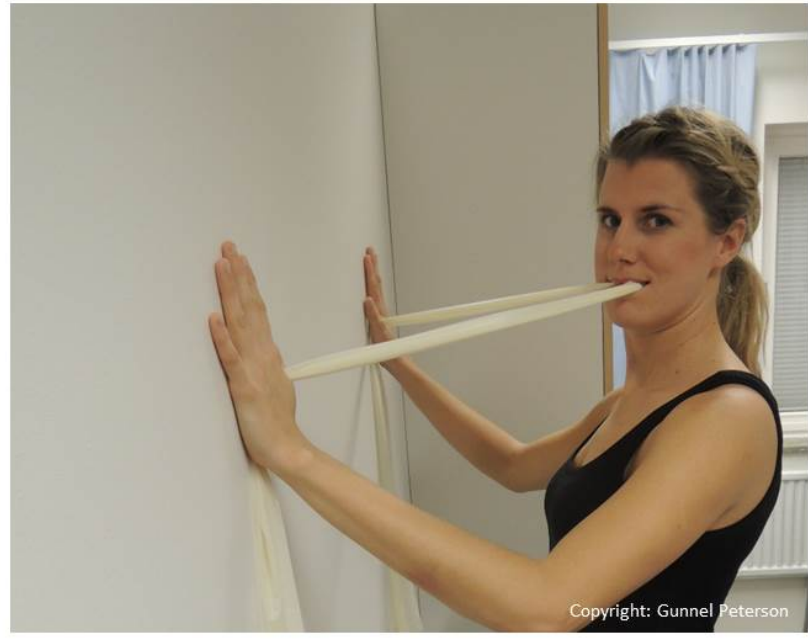

In a standing position, hold the ends of the rubber band against a wall, with the hands apart (do not lean against the wall). Keeping the middle of the rubber band gently between the teeth, gently turn the head from side-to-side.

Copyright: Gunnel Peterson/ Maria Landén Ludvigsson/Anneli Peolsson. This document is intended for physiotherapists only and may be copied and used by physiotherapists in their professional clinical conduct, with due credit given to the authors. The exercises shall be reassessed by trained professionals and may need adjustments in each specific case. Furthermore, the results presented in this document are the result of university research and shall not be seen as a commercial product. The authors shall have no liability whatsoever for any use. All responsibility for the congruity and use of the contents herein rests entirely with the therapist using it. No alterations to this document, or further distribution in any form without explicit permission from copyright holders, is allowed, except with regards to the rights previously mentioned. 